ABE375SPAN

\title{
Instalación de Obturadores De Ventanas ${ }^{1}$
}

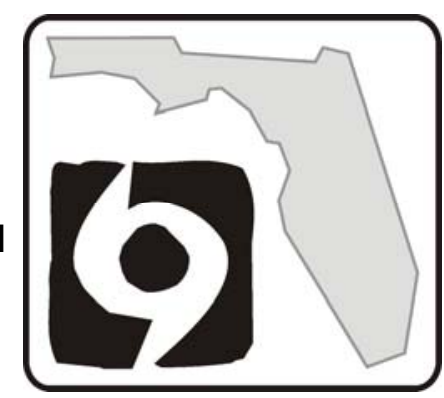

Hal S. Knowles, III, Kathleen C. Ruppert, Karla A. Lenfesty, y Barbara Haldeman²

Ventanas desprotegidas son los lugares más comunes donde los daños de tormenta ocurren. Como se describe en nuestro documento, ¿Qué tan segura es su casa?, ventanas rotas pueden permitir la entrada a vientos y lluvia a su casa y hasta provocar que su techo fracase.

\section{¿Qué Hace A Una Ventana Segura?}

La gente comúnmente utiliza cinta adhesiva para proteger las ventanas. Usar cinta adhesiva NO aumenta la resistencia del vidrio y $N O$ protegerá su casa de escombros que puedan estar en el aire.

Ventanas reforzadas contra impacto pueden fracasar cuando el marco de la ventana esta bajo la presión de los vientos y escombros. Similarmente, ventanas con plástico ó películas no son una medida de protección. La mejor manera de proteger sus ventanas es instalando obturadores.

\section{¿Cómo Puedo Escoger El Obturador Adecuado?}

Cada dueño de vivienda debe instalar obturadores que mejor se adapte a sus necesidades individuales. Factores como costo, fácil instalación y grado de protección deben ser considerados.

Los obturadores proveen protección contra el impacto de objetos en el aire y escombros y/ó la presión de vientos en ventanas, puertas francesas, ventanas y puertas corredizas, así como otras aberturas. No importa que tipo de obturadores usted escoja, propia instalación es importante para asegurar el mejor funcionamiento.

\section{Problemas Adicionales Que Considerar}

Si máxima protección es su meta, esté seguro de seleccionar productos aprobados por los estándares del Condado Miami Dade (vea la conección de búsqueda de productos abajo). Simplemente instalar obturadores no es suficiente. Es importante usar técnicas de construcción apropiadas para mantener sus obturadores fuertes y reducir el potencial de impacto de escombros en el aire. Estos problemas incluyen:

- Asegurar objetos que estén afuera incluyendo muebles de patio, basureros, canastas de reciclaje, potes de plantas, etc.

- Instalar obturadores al marco de la estructura de su casa, $N O$ a ventanas ó marcos de puertas.

- Utilizar materiales anticorrosivos para todas las partes expuestas del sistema de obturadores incluyendo los paneles y seguros.

\section{Otros Recursos:}

\begin{abstract}
Miami-Dade County | Building Code Compliance Product Search http://www.miamidade.gov/buildingcode/online_pr oduct_search.asp
\end{abstract}

NOAA \& AOML / Hurricane Shutters (FAQ) http://www.aoml.noaa.gov/hrd/shutters/index1.html

1. Este documento es Parte 2 de 5 en Educación + Acción = Series de Mitigación en Daños de Vientos. Día de publicación: Noviembre 2005.

2. Hal S. Knowles, III, Coordinador, Program for Resource Efficient Communities; Kathleen C. Ruppert, Científico de Extensión Asociado, Florida Energy Extension Service; Karla A. Lenfesty, Especialista del Programa de Mitigación en Daños de Tormentas de Vientos, St. Lucie County Cooperative Extension, Institute of Food and Agricultural Sciences, University of Florida; Barbara Haldeman, Asistente Editorial, Florida Energy Extension Service.

The Institute of Food and Agricultural Sciences (IFAS) es un Empleador de igualdad de oportunidad autorizado para proveer investigación, información educacional y otros servicios a individuos e instituciones que funcionen sin discriminación de raza, credo, color, religión, edad, inhabilidad, sexo, orientación sexual, estado civil, origen de nacionalidad, opinión ó afiliación política. Para información de cómo obtener otras publicaciones de extensión, contacte la oficina de Cooperative Exntension Service de su Condado. Florida Cooperative Extension Service / Institute of Food and Agricultural Sciences / University of Florida / Larry R. Arrington, Decano.

Publicación parcialmente financiada por Florida Department of Community Affairs Residential Construction Mitigation Program Grant. 


\section{¿Qué Obturadores Hay Disponibles?}

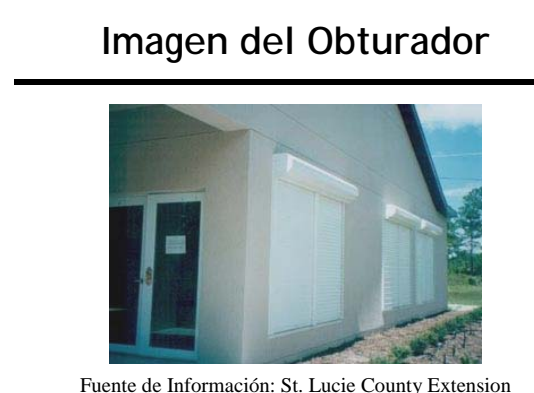

Fuente de Información: St. Lucie County Extension

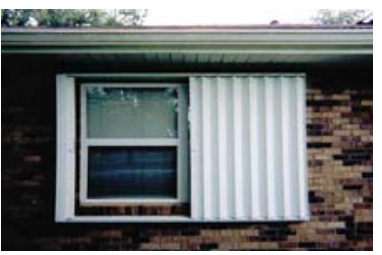

Fuente de Información: www.hurricaneshuttercompany.com

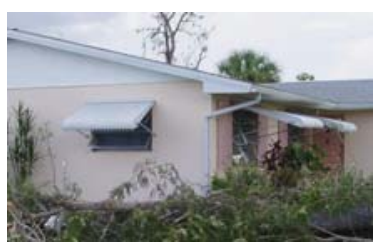

Fuente de Información: Florida Coastal Monitoring Program
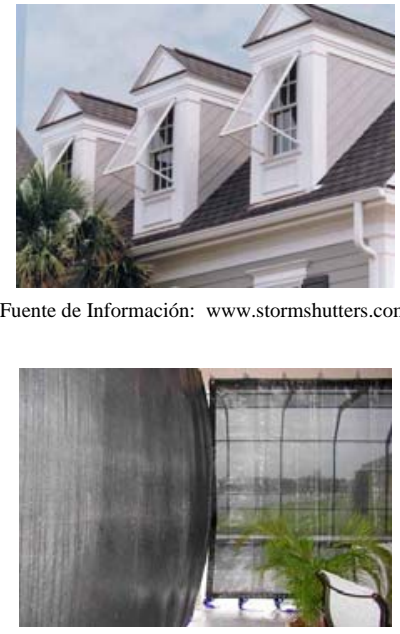

Fuente de Información: www.stormshutters.com

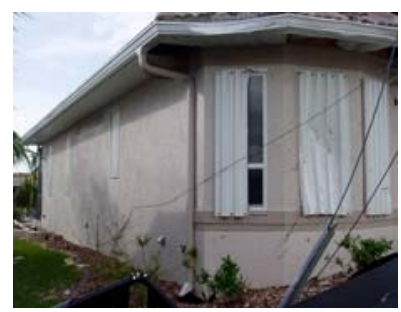

Fuente de Información: Florida Coastal Monitoring Program

$N / A$
Tipos de Obturadores y Detalles

Desenrollo Automático

Estos obturadores desenrollan desde un montaje de la caja en la parte superior de cada ventana ó puerta a proteger. Son generalmente hechos de metal y asegurados en la parte inferior.

Pros: preinstalados, fácil de usar y pueden ser motorizados.

Cons: muy caros.

\section{Acordeones}

Estos obturadores son halados juntos de cada lado de la abertura a proteger. Son generalmente hechos de metal y asegurados juntos ó en el separador del medio.

Pros: preinstalados y fácil de usar.

Cons: algo caros y la arquitectura no es muy atractiva.

\section{Toldas}

Estos obturadores se bajan y aseguran en posición. Están hechos de metal o fibra de vidrio y proporcionan sombra en las ventanas cuando no están en uso.

Pros: preinstaladas y fácil de usar.

Cons: algo caras y la arquitectura no es muy atractiva.

\section{Tolda Bahama y Obturador Colonial}

Estos obturadores de panel de persianas son toldas (que proporcionan sombra parcial cuando no se usan) ó estilo Colonial.

Pros: preinstaladas, fácil de usar y atractiva arquitectura.

Cons: algo caras y la resistencia varía con el diseño.

\section{Mallas contra Huracán}

Estos obturadores están hechos de una tela reforzada

parcialmente porosa que reduce la presión del viento y daños de impacto de escombros.

Pros: baratas, permiten que la luz traspase y fácil de guardar.

Cons: tecnológicamente nuevas, el impacto de escombro puede dañar las ventanas en contacto con la malla y son mejores para aberturas sin cristales.

\section{Páneles de Tormenta}

Estos obturadores deben ser guardados e instalados temporalmente para una tormenta. Están hechos de acero ó aluminio que son asegurados a un canal preinstalado de acero en la parte superior/inferior de la abertura a proteger ó pueden ser anclados ó atornillados directamente a la casa.

Pros: baratas, fuertes

Cons: pesados, difícil de instalar y guardar.

\section{Plywood}

Para mas información, vea nuestro documento "Protegiendo con Plywood”.
Precio $\$ \$ \$ \$$ 